\title{
The effects of load variability in short-term memory task'
}

STANLEY M. MOSS, JOHM B. SOWARD, AND JOSEPH F. HEARMS

UNIVERSTTY OF MASSACHUSETTS

Six groups of Ss viewed briefly exposed arrays of letters, half designated high-valued and half low-valued. Immediately after each exposure Ss wrote down as many of the stimuli as they could remember. For three groups, the number of letters in each exposure was constant from trial to trial; for the remaining three groups, the number of letters in each exposure varied from trial to trial. This tested the hypothesis that load variability influences the development of an efficient response strategy which, in turn, affects the processing of information stored in short-term memory. The data supported this hypothesis. Performance was superior under the constant load condition due to the ability of these Ss to correctly report both high- and low-valued letters. Poor performance was observed under the variable load condition because of a decrease in the number of low valued letters correctly reported.

The results of a recent study which induced selective retrieval from short-term memory by imposing high and low values on displayed targets (Moss, Hearns, \& Soward, 1966) indicated that selection of a response strategy was important in optimizing information processing in short-term memory. The selection of a response strategy was, in part, determined by the ratio of the rewards associated with high-valued targets as compared to those associated with low-valued targets. The higher this ratio the greater the mutual interference between the targets, resulting in a reduction in the number of targets accurately reported. In addition, the low levels of overall responding and trial-to-trial fluctuations in the number and accuracy of targets reported suggested that Ss were not adopting optimal and consistent response strategies.

Moss et al suggested that one reason for S's inability to adopt a consistent strategy was due to the trialto-trial variation in load (the number of targets simultaneously presented). In other words, when there was variation in load within a sequence of presentations, Ss could not adopt a specific strategy. If this is true, then constant load presentations from trialto-trial would enable $S s$ to adopt and eventually refine such a strategy.

It was further suggested that trial-to-trial load variation would produce effects on other variables known to influence information processing in shortterm memory. Other investigators, Teichner, Dahlquist, and Pesner (1963), Selbel, Christ, and Teichner (1964), and Taub (1965), have indicated that the amount of information which can be extracted from briefly exposed stimuli is limited more by the conditions involved in the storage and extraction of information such as value than by input variables such as load. Since differential responding to high and low valued targets reflects, in part, $\mathrm{Ss}^{\prime}$ strategies, it is predicted that trial-totrial load variation will effect this differential responding.

The purpose of the present experiment was to test these hypotheses by assessing Ss' strategy, accuracy, and item processing within the context of short-term memory by manipulating trial-to-trial load variability.

\section{Subjects \\ The Ss were 48 undergraduates from the University of Massachusetts introductory psychology courses. All received course credit for participation and monetary rewards based on performance in the experiment.}

\section{Stimulus Materials and Apparafus}

The first 10 letters, A-J, and the last 10 letters, $\mathrm{O}-\mathrm{Z}$, of the English alphabet provided two subsets of category value. To create a clear distinction between subsets, the letters K-P were never used.

Stimulus displays were 336 slides with white upper case letters on a black background. Slides varied in number of targets (load) with each letter of the alphabet representing a target. The six levels of load were $2,4,6,8,12$, and 16 letters per slide, with 84 slides from loads 4,8 , and 12 and 28 slides from loads 2, 6, and 16. Each level of load was replicated with a different random sample of the alphabet with the restriction that within each alphabet half (A-J and $Q-Z)$, the letters appear with equal frequency over the slides. Letters were then randomly assigned to a location within a 10 by 10 matrix; on the average, one-half the letters selected from each subset were placed in the center 36 positions of the matrix, and the other half were placed in the 64 peripheral positions. Upper case letters were typed on unlined white cards with typewriter spaces as matrix cells. The cards were photographed on $35 \mathrm{~mm}$ negative film from which slides were made for projection.

A Kodak Carousel slide projector, wired for automatic control of slide exposure and inter-slide interval, projected $40 \times 60 \mathrm{in}$. images with letters of $1.5 \times$ 1 in. Groups of four Ss sat in alternate chairs in a small classroom. The average distance from $\mathrm{Ss}$ to the projected letters was $10 \mathrm{ft}$. 


\section{Design and Procedure}

The Ss were divided into groups based upon six different Mean Load by Load Variability combinations. Mean Load refers to the average number of targets per slide (either 4,8 , or 12) with 16 Ss assigned to each Mean Load. Half of the Ss at each Mean Load viewed a constant load sequence (either 4,8 , or 12) while the other half viewed a variable load sequence (either 2-4-6, 4-8-12, or 8-12-16). An experimental session consisted of seven successive blocks of 12 slide presentations. This experimental design constituted a 3 by 2 by 2 by 7 factorial with Mean Load and Load Variability as between-Ss variables and Value and Blocks as within-Ss variables.

The sequence of slide presentations within each block of trials was randomized with the following exception: All the load 4, 8, and 12 slides under the three variable load conditions appeared in the same serial position under the constant load conditions. Specifically, if the four load 12 slides appeared in serial positions 2 , $5,7,9$, and 11 under the variable load conditions, then these same slides appeared in the same serial positions under the constant load condition. In the subsequent analyses those slides were sampled from the constant load sequence that appeared in the same serial position of the comparable variable load condition. This provided a means for sampling equal numbers of load presentations within a block of trials.

To familiarize Ss with the working conditions and with the task in general, each $\mathrm{S}$ was given a card listing the two subsets of letters and indicating which halves were high-and low-valued. For half the Ss the A-J letters were designated as high-valued while the $Q-Z$ letters were designated as high-valued for the remaining Ss. All groups worked at a 4:1 value ratio, i.e., Ss received 4 points for every high-valued target correctly reported and 1 point for every low-valued target correctly reported. Payoff was based on total points accumulated for correct responses.

During training, Ss viewed three slides, one representing each Mean Load condition, while E explained how points would be tallied.

During the experiment, Ss viewed 84 slides with a $5-$ min rest after the 48 th slide. After a $.5 \mathrm{sec}$ buzzer signalling the start of a trial, there was a 1-sec preparation period. Each slide was exposed for .75 sec; Ss were given $7.25 \mathrm{sec}$ to write down their responses.

\section{RESULTS AND DISCUSSION}

In order to assess $\mathrm{Ss}^{\prime}$ response strategy, performance, and item processing, the following three dependent measures were obtained: (1) the total number of targets reported; (2) the number of correct targets reported; and (3) the number of correct first reports. Measures (2) and (3) differ in that the former considers S's total number of correct responses to a slide whereas the latter considers only the initial response made. Two additional measures, the percentage correct of responses made (the total number of correct responses divided by the total number of responses made) and the percentage correct of responses available (the number of correct responses divided by the number of targets presented) were also computed. However, these measures proved to be generally insensitive to the experimental manipulations.

The data for the analyses of the three dependent measures were obtained from the respective total responses for each load and value within a block of trials for each $\mathrm{S}$. For the Variable Load conditions the means for the three load totals were used. Note that only four trials were sampled within each block of trials for the Constant Load conditions.

Analysis of total responses made indicates that Mean Load was significant $(F=4.34$, df $=2 / 42, p<.05)$. Specifically, the average total responses for Mean Loads of 4,8 , and 12 , were $18.2,21.0$, and $21.8 \mathrm{re}$ sponses. The main effect of value was also significant ( $F=15.19, \mathrm{df}=1 / 42, \mathrm{p}<.01$ ), with an average of 21.1 high-valued, and 19.6 low-valued targets reported. Figure 1 shows the significant increase in total responding as a function of trial Blocks ( $F=27.55$, $d f=6 / 252, p<.01)$. Differences between the variability groups did not achieve significance. There was, however, a significant Variability by Blocks interaction ( $F=$ $2.36 \mathrm{df}=6 / 252, \mathrm{p}<.01$ ). While there was an increase in total responding over trial blocks for both load variability groups, the rate of increase was much greater for the constant load group. It should be noted that while the mean loads for the two variability groups are equal, the groups differ in trial-to-trial load variation; it is this latter factor that produced decreased total responding by the high variability group.

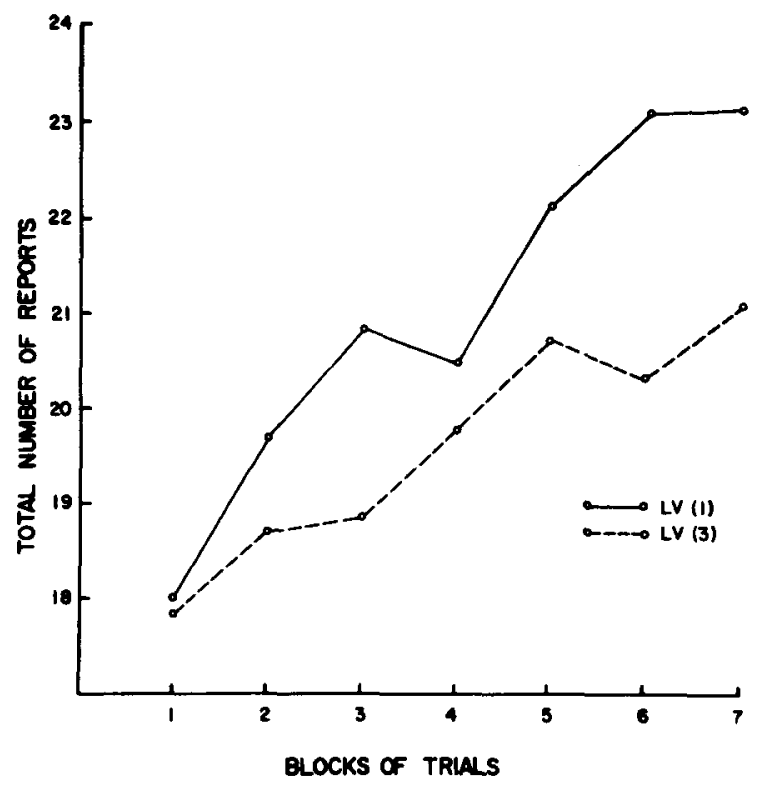

Fig. 1. Total number of targets reported as a function of triál blocks with Load Variability as a parameter. 


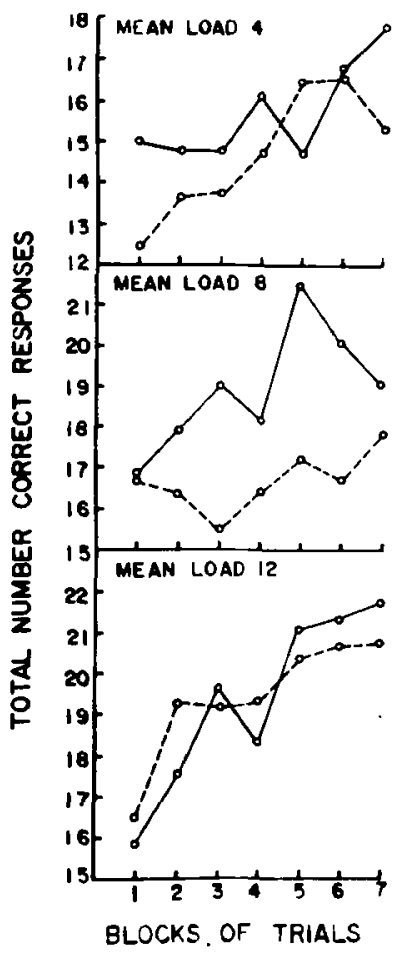

Fig. 2. The number of correct responses as a function of trial blocks with Mean Load and Load Variability as parameters.

Analysis of the total number of correct responses made yields trends similar to those obtained for total responding for the main effects of Mean Load, Value, and Blocks. Figure 2 summarizes the significant Load Variability by Mean Load by Blocks interaction ( $F=$ 2.70, $\mathrm{df}=12 / 252, \mathrm{p}<.01)$. There was an increase in the number of targets correctly reported over trial blocks for each mean load at each level of load variability with terminal behavior (Block 7) exhibiting a clear load variability effect for each of the mean load levels.

It is interesting that Mean Load 8 shows the largest load variability differentiation for the number of targets reported correctly. At this mean load, Ss are responding correctly significantly more often $(t=3.561, p<\quad .05)$ to the constant load condition than to the variable load (4-8-12) condition.

The greater accuracy for the higher mean loads is related to the increased availability of information to report rather than an increased tendency for Ss to guess. This was demonstrated in a similar task by Soward (1967) who compared correct responses and errors across load. It was shown that the errors were much smaller than would have been predicted had Ss been guessing and correct responses were well within the span of immediate memory which would not have been so had Ss been guessing.

If there is differential item processing in short term memory, it follows that the number of correct first reports should indicate a favoring of high-valued targets. This assumption was born out as seen by the significant value effect $(F=26.92, d f=1 / 42, p<.01)$; there was an average of 6.6 correct high- and 4.8 correct low-valued first reports.

An additional evaluation of performance was obtained by partitioning the data for between- and within-S load variability. Performance for the Mean Load 8 group under the high variability condition (within-S) was compared with performance across the entire low variability group (between-S). Means were computed for this partitioning with Value as the major parameter.

Table 1 lists these means for the three dependent measures used in the present study. It is apparent that between- and within-S variation of load create different overall responding rates and levels of accuracy. On the average, more total reports were made when load varied as a between-S variable. These results are consistent with the data reported above; overall responding and accuracy were greater for the low load variability group than for the high variability group. Of particular interest is the difference in the value effects under this partition. The means of the total number of targets reported indicate that highvalued targets were reported with about equal frequency for both data partitions. There was considerable difference, however, in the number of low-valued targets reported; the between-S totals exceeded the within-S totals. Accuracy of reporting is consistent with total reports. These differences account for the overall greater number of reports made and the greater accuracy for between-S variation, i.e., more targets reported and greater accuracy for the low-valued targets.

These results indicate that load variability influences the processing of items in short-term memory in such a way that an optimal response strategy is not adopted. Dale (1964), who obtained an interaction between search strategies and memory processes, provides a possible explanation of the present results. Dale found that memory for tests to find a target varied according to search strategy; the less systematic the search the more readily the tests were forgotten. If load variability has the effect of making visual search unsystematic, then the targets originally seen would be more readily forgotten. If load constancy makes search systematic,

Table 1. Means for the Three Dependent Measures Partitioned for Within- and Between-S Load Variation at Mean Load 8.

With in-S Load Variation Between-S Load Variation High Value Low Value High Value Low Value

\begin{tabular}{lcccc}
\hline $\begin{array}{l}\text { Total number of } \\
\text { targets reported }\end{array}$ & 22.3 & 16.8 & 22.6 & 19.5 \\
$\begin{array}{l}\text { Number of correct } \\
\text { targets reported }\end{array}$ & 18.6 & 14.6 & 19.3 & 16.7 \\
$\begin{array}{l}\text { Number of correct } \\
\text { first reports }\end{array}$ & 6.8 & 4.3 & 6.7 & 4.6 \\
\hline
\end{tabular}


then the targets should be available longer in shortterm memory and enable $S$ to implement his particular response strategy. The results of the present experiment support this conclusion; more targets are correctly reported under the Constant Load Condition. As an additional test, Ss' search strategies should be assessed to determine their relationships to item processing in short-term memory.

\section{References}

Dale, H. C. A. Factors affecting choice of strategy in searching. Ergonomics, 1964, 7, 73-82.

Moss, S. M., Hearns, J. F., \& Soward, J. B. Factors affecting information processing in short-term memory. ONR Technical Report No. 2 NR 196-043, December 1966.
Seibel, R., Christ, R. E., \& Teichner, W. H. Perception and short term memory under work load stress. J. exp. Psychol., 1965 70, 154- 162 .

Soward, J. B. The effects of Value Ratio Shifts on item processing in short term memory, Unpublished Masters Thesis, University of Massachusetts, 1967.

Taub, H. A. Effects of differential value on recall of visual symbols. J. exp. Psychol., 1965, 69, 135-143.

Teichner, W. H., Dahlquist, E., Eddy, N., \& Pesner, s. Experiments on the effects of input variables on multitarget alphabetic displays. Technical Documentary Report, No. ESD-TDR-63-546, Decision Sciences Laboratory, Air Force Systems Command, Hanscomb Field, Massachusetts, 1963.

\section{Note}

1. This research was supported by ONR Contract NR 196-043.

(Accepted for publication February 13, 1968.) 